\title{
Tauroursodeoxycholic acid mediates endoplasmic reticulum stress and autophagy in adrenocortical carcinoma cells
}

\author{
XUEMEI HUANG ${ }^{1}$, LILI WU $^{2}$, YAQI KUANG ${ }^{1}$, XIN LI $^{1}$, XIUJUN DENG $^{1}$, XINGHUAN LIANG $^{1}$, \\ LI LI $^{1}$, HAIYAN YANG ${ }^{1}$, ZHENXING HUANG ${ }^{1}$, DECHENG LU ${ }^{1 *}$ and ZUOJIE LUO ${ }^{1 *}$ \\ ${ }^{1}$ Department of Endocrinology, The First Affiliated Hospital of Guangxi Medical University; \\ ${ }^{2}$ Department of Integrated Medicine, The Affiliated Tumour Hospital of \\ Guangxi Medical University, Nanning, Guangxi 530021, P.R. China
}

Received April 13,2019; Accepted September 27, 2019

DOI: $10.3892 / 01.2019 .11057$

\begin{abstract}
Adrenocortical carcinoma (ACC) is an invasive tumor that occurs in the endocrine system. Increasing evidence has shown that endoplasmic reticulum (ER) stress and autophagy play an important role in tumor formation. Tauroursodeoxycholic acid (TUDCA) is an ER chemical chaperone that can alleviate ER stress. In the present study, TUDCA promoted the proliferation, migration and invasion of ACC SW-13 and NCI-H295R cells. Reverse transcription-quantitative PCR and western blot analysis showed that the expression of glucose-regulated protein 78, a promoter of ER stress, was decreased. The expression levels of protein kinase R (PKR)-like ER kinase and activating transcription factor 6 were correspondingly decreased, and the downstream proteins, C/EBP homologous protein and JNK, were also decreased. The expression levels of the autophagy factor microtubule-associated protein light chain 3-II/I and the anti-apoptotic factor Bcl-2 increased following TUDCA treatment, while the expression of the pro-apoptotic factor Bax decreased. TUDCA alleviated ER stress in ACC SW-13 and NCI-H295R cells and induced autophagy, thereby inhibiting
\end{abstract}

Correspondence to: Professor Zuojie Luo or Professor Decheng Lu, Department of Endocrinology, The First Affiliated Hospital of Guangxi Medical University, 6 Shuangyong Road, Nanning, Guangxi 530021, P.R. China

E-mail: luozuojie@gxmu.edu.cn

E-mail: ludecheng@gxmu.edu.cn

*Contributed equally

Abbreviations: ACC, adrenocortical carcinoma; ER, endoplasmic reticulum; TUDCA, tauroursodeoxycholic acid; UPR, unfolded protein response; PERK, protein kinase R-like ER kinase; eIF2 $\alpha$, eukaryotic initiation factor-2 $\alpha$; ATF4, activating transcription factor 4; GRP78, glucose-regulated protein 78; IRE1 $\alpha$, inositol-requiring protein $1 \alpha$

Key words: adrenocortical carcinoma, tauroursodeoxycholic acid, endoplasmic reticulum stress, autophagy, apoptosis
ACC cell apoptosis. ER stress- and autophagy-related signaling pathways are involved in the occurrence of ACC, which may provide potential therapeutic targets for ACC treatment.

\section{Introduction}

Adrenocortical carcinoma (ACC) is a rare endocrine malignancy, with an incidence rate of 1.5 to 2 cases per million people per year worldwide (1). Albeit rare, ACC is often aggressive and lethal, with $10-20 \%$ of patients surviving 5 years after diagnosis (2). To date, the main curative therapy for ACC is surgical resection of the primary tumor. However, most patients with an advanced stage of the disease have a median survival time of $<12$ months, even after complete tumor resection (3). Even with ostensibly complete resections, the rates of local recurrence have typically ranged from at least 19 to $34 \%$ in those patients with no residual disease after surgery $(4,5)$. Mitotane remains the only drug approved for ACC treatment by the U.S. Food and Drug Administration and European Medicine Executive Agency (6). However, mitotane is an adjuvant therapy for patients with low to moderate risk for ACC recurrence, and its efficacy is ultimately limited by its high lipophilicity, poor pharmacokinetic properties, and dose-limiting toxicities (7). In addition, long-term radiotherapy may be used in patients at an increased risk of local recurrence (8). The high degree of malignancy, strong invasiveness, poor traditional treatment efficacy and poor prognosis of ACC have led to the exploration of targeted therapy.

A recent study has demonstrated that endoplasmic reticulum (ER) stress may play an important role in the development of cancer (9). Alterations in the homeostasis and appropriate functioning of the ER initiates a cascade of signaling events known as the ER stress response or unfolded protein response (UPR). When ER stress occurs, cancer cells in colorectal, breast and cervical cancer, adapt the UPR to alleviate the ER stress condition as a survival approach for progression $(10,11)$. Adaptation of cancer cells to adverse conditions largely relies on the ability of a cell to perturb ER stress-associated regulatory networks and prevent ER stress-induced cell death $(12,13)$. Autophagy is a highly conserved system that delivers misfolded proteins and damaged organelles to the lysosome for degradation, maintaining cell homeostasis (14). Li et al (15) showed 
that the ER stress-responsive protein kinase R-like ER kinase (PERK)-eukaryotic initiation factor-2 $\alpha$ (eIF2 $\alpha$ )-activating transcription factor (ATF) 4 pathway contributes to ER stress-induced autophagy. Persistent ER stress often results in the stimulation of autophagic activities (16).

Tauroursodeoxycholic acid (TUDCA) is a chemical chaperone that stabilizes protein conformation and improves the folding capacity of the ER (17). Yang et al (18) showed that TUDCA could downregulate ER stress in a dose-dependent manner using human hepatocellular carcinoma cells. Guo et al (19) found that TUDCA reversed abnormal autophagy and reduced ER stress in the liver of obese mice. Therefore, TUDCA is a promising regulator for mediating ER stress, which significantly relieves ER stress and inhibits cell apoptosis in the aforementioned cells.

The present study aimed to identify whether ER stress and autophagy are involved in the occurrence of ACC by TUDCA interventions, providing a theoretical basis for the treatment of ACC.

\section{Materials and methods}

Cell culture. The SW-13 cell line was obtained from Shanghai Institutes for Biological Sciences, Chinese Academy of Sciences (cat. no. TCHu221). The NCI-H295R cell line was obtained from the American Type Culture Collection (cat. no. ATCC ${ }^{\circledR}$ CRL-2128). Cells were grown in minimum essential medium supplemented with $10 \%$ fetal bovine serum (Gibco; Thermo Fisher Scientific, Inc.) and 1\% penicillin-streptomycin solution (Beijing Solarbio Science and Technology Co., Ltd.). Cells were cultured at $37^{\circ} \mathrm{C}$ in a humidified atmosphere with $5 \% \mathrm{CO}_{2}$ and 95\% humidity in an incubator. TUDCA was purchased from EMD Millipore. SW-13 cells were treated with 0, 100, 200, 300 or $400 \mu \mathrm{M}$ TUDCA, and NCI-H295R cells were treated with $0,100,200,400$ or $600 \mu \mathrm{M}$ TUDCA.

Cell proliferation assay. SW-13 and NCI-H295R cells were seeded in 96-well plates at a density of $1 \times 10^{3}$ cells/well and allowed to attach for $24 \mathrm{~h}$. Then, the cells were treated with different concentrations of TUDCA as aforementioned. The cells were incubated at $37^{\circ} \mathrm{C}$ for $12,24,48$ and $72 \mathrm{~h}$. Then, cell proliferation was assessed using a Cell Counting Kit 8 (CCK8) assay (Dojindo Molecular Technologies, Inc.) according to the manufacturer's instructions. Finally, the optical density at $450 \mathrm{~nm}$ was detected and cell proliferation calculated. Each set of experiments was performed in triplicate.

Cell migration assay. After SW-13 and NCI-H295R cells were resuspended with trypsin (Gibco; Thermo Fisher Scientific, Inc.), $5 \times 10^{5}$ cells/well were seeded in 6 -well plates and incubated in $10 \%$ serum-containing minimal essential medium (Gibco; Thermo Fisher Scientific, Inc.) at $37^{\circ} \mathrm{C}$ for $24 \mathrm{~h}$. When the cells reached $100 \%$ confluence, scratches on the cells were made perpendicular to the well plate with a small tip. The well plates were washed once with PBS to remove the dislodged cells. Then, SW-13 and NCI-H295R cells were treated with different concentrations of TUDCA as aforementioned. The cells were cultured in serum-free minimal essential medium at $37^{\circ} \mathrm{C}$. Migration was visualized at $0,6,12$, and $24 \mathrm{~h}$ with an inverted light microscope (TE2000; Nikon Corporation).
Migration distances were measured using ImageJ software version 1.8.0 (National Institutes of Health).

Transwell invasion assays. SW-13 and NCI-H295R cells were treated with aforementioned concentrations of TUDCA. The cells were cultured in serum-free medium for $24 \mathrm{~h}$ at $37^{\circ} \mathrm{C}$. Then, the upper chambers were precoated with Matrigel matrix (Corning, Inc.), and cells were added to the upper chambers at a concentration of $1 \times 10^{5}$ cells per well. Next, $500 \mu 1$ serum-containing medium was added to the lower chambers. After $24 \mathrm{~h}$ of incubation, the cells on the upper side of the filters were removed with a cotton swab, and the filters were washed with PBS. The cells were fixed in methanol for $30 \mathrm{~min}$ at room temperature, and nuclei were stained with $0.1 \%$ crystal violet for $15 \mathrm{~min}$ at room temperature. Images were captured under a light microscope, and cell counts were measured using Image J software version 1.8.0 (National Institutes of Health).

Reverse transcription-quantitative PCR (RT-qPCR) analysis. Total RNA was extracted from SW-13 cells cultured in different concentrations of TUDCA $(0,100,200,300$, or $400 \mu \mathrm{M}$ for 48 h) using RNAiso Plus reagent (Takara Biotechnology Co., Ltd.). Following RNA extraction, cDNA was synthesized using a Takara RT kit (Takara Biotechnology Co., Ltd.) at $37^{\circ} \mathrm{C}$ for $15 \mathrm{~min}, 85^{\circ} \mathrm{C}$ for $5 \mathrm{sec}$ and kept at $4^{\circ} \mathrm{C}$ until further experimentation. qPCR amplification was conducted with SYBR-Green reagent (Takara Biotechnology Co., Ltd.) using an ABI 7500 sequencer (Applied Biosystems; Thermo Fisher Scientific, Inc.) and the following conditions were used: Initial denaturation at $95^{\circ} \mathrm{C}$ for $30 \mathrm{sec}$, then 40 cycles of $95^{\circ} \mathrm{C}$ for $5 \mathrm{sec}$ and $60^{\circ} \mathrm{C}$ for $34 \mathrm{sec}$. The experimental steps were carried out according to the manufacturer's instructions. The primers were designed and synthesized by Sangon Biotech Co., Ltd. (Table I). $\mathrm{C}_{\mathrm{q}}$ values were generated using the default analysis settings. $\Delta \mathrm{C}_{\mathrm{q}}$ was calculated using the following formula: $\left(\mathrm{C}_{\mathrm{q}}\right.$ gene of interest $)-\left(\mathrm{C}_{\mathrm{T}} \mathrm{GAPDH}\right) . \Delta \Delta \mathrm{C}_{\mathrm{q}}$ was calculated using the following formula: $\left(\Delta \mathrm{C}_{\mathrm{q}}\right.$ treated sample $)-\left(\mathrm{C}_{\mathrm{q}}\right.$ control sample). Relative expression was calculated using the $2^{-\Delta \Delta \mathrm{Cq}}$ method as previously described (20).

Western blot analysis. SW-13 cells were treated with aforementioned concentrations of TUDCA. After 48 h, SW-13 cells were lysed with RIPA lysis buffer containing $1 \mathrm{mM}$ PMSF (Beijing Solarbio Science and Technology Co., Ltd.) for $30 \mathrm{~min}$ then the cells were centrifuged at $14,000 \mathrm{xg}$ for $10 \mathrm{~min}$ at $4^{\circ} \mathrm{C}$, and the supernatant was collected. Subsequently, the protein concentration was determined using a BCA protein analysis kit (Beyotime Institute of Biotechnology). A total of $50 \mu \mathrm{g}$ of total protein was separated using 10\% SDS-PAGE and transferred to PVDF membranes (Sigma-Aldrich; Merck KGaA). The membranes were blocked using 5\% skimmed milk at room temperature for $1 \mathrm{~h}$ and then incubated with primary antibodies at $4^{\circ} \mathrm{C}$ overnight. Next, the membranes were washed three times with TBS-Tween 20 and incubated with secondary horseradish peroxidase-conjugated antibody (dilution 1:10,000; cat. no. L3012-2; Signalway Antibody LLC) for $1 \mathrm{~h}$ at room temperature. The protein bands were imaged using a densitometric scanner (Bio-Rad Laboratories, Inc.) and analyzed with ImageJ software version 1.8.0 (National Institutes of Health). Antibodies against PERK (dilution 1:1,000; cat. no. 3192), 
Table I. Primer sequence for reverse transcription-quantitative PCR.

\begin{tabular}{ll}
\hline Gene name & \multicolumn{1}{c}{ Primer sequence (5'-3') } \\
\hline GAPDH & F: CAGGAGGCATTGCTGATGAT \\
R: GAAGGCTGGGGCTCATTT \\
F: CAGTTGTTACTGTACCAGCCTA \\
R: CATTTAGGCCAGCAATAGTTCC \\
FERK & F: CCAGTTTTGTACTCCAATTGCA \\
& R: CAGATACAGCTGGCCTCTATAC \\
CHOP & F: GAGAATGAAAGGAAAGTGGCAC \\
& R: ATTCACCATTCGGTCAATCAGA \\
JNK & F: ACACCACAGAAATCCCTAGAAG \\
ATF6 & R: CACAGCATCTGATAGAGAAGGT \\
& F: CTGATGGCTGTTCAATACACAG \\
LC3-II/I & R: GATCCCTTCGAAATGACACAAC \\
& F: AGCCCGTTTCTTTCATCATAACATC \\
Bax & R: AAGATCTAAGCCTGTGCCATTTAC \\
& F: CGAACTGGACAGTAACATGGAG \\
Bcl-2 & R: CAGTTTGCTGGCAAAGTAGAAA \\
& F: GACTTCGCCGAGATGTCCAG \\
& R: GAACTCAAAGAAGGCCACAATC
\end{tabular}

F, forward; R, reverse; GRP78, glucose-regulated protein 78; PERK, protein kinase R-like ER kinase; $\mathrm{CHOP}, \mathrm{C} / \mathrm{EBP}$ homologous protein; ATF6, activating transcription factor 6; LC3, microtubule-associated protein light chain 3 .

JNK (dilution 1:1,000; cat. no. 9252), ATF6 (dilution 1:1,000; cat. no. 65880), C/EBP homologous protein (CHOP; dilution 1:1,000; cat. no. 2895), microtubule-associated protein light chain 3 (LC3)-II/I (dilution 1:1,000; cat. no. 2775), Bax (dilution 1:1,000; cat. no. 2772) and Bcl-2 (dilution 1:1,000; cat. no. 3498) were purchased from Cell Signaling Technology, Inc. Antibodies against glucose-regulated protein 78 (GRP78; dilution 1:1,000; cat. no. 33395) and GAPDH (dilution 1:5,000; cat. no. 21612) were purchased from Signalway Antibody LLC.

Statistical analysis. All experiments were repeated three times, and the data were analyzed using SPSS version 17.0 software (SPSS, Inc.). Graphical representation of data was prepared with GraphPad Prism version 5.0 software (GraphPad Software, Inc.). The data are expressed as the mean \pm standard deviation. Differences in the data among the groups were analyzed using one-way ANOVA combined with Bonferroni's post hoc test. $\mathrm{P}<0.05$ was considered to indicate a statistically significant difference.

\section{Results}

TUDCA promotes the proliferation, migration, and invasiveness of ACC cells. The effects of TUDCA on SW-13 and NCI-H295R cell proliferation, motility, and invasiveness were investigated. The proliferation of SW-13 and NCI-H295R cells after treatment with different concentrations of TUDCA was measured using a CCK8 assay. The CCK8 assay revealed that TUDCA promoted SW-13 and NCI-H295R cell proliferation. TUDCA at a concentration of $400 \mu \mathrm{M}$ significantly promoted the proliferation of SW-13 cells, while $600 \mu \mathrm{M}$ TUDCA significantly promoted NCI-H295R cell proliferation (Fig. 1A and B).

Since the migration and invasion of cancer cells are crucial factors responsible for cancer progression (21), the effect of TUDCA on SW-13 and NCI-H295R cell migration and invasion was examined. The wound healing assays revealed that SW-13 and NCI-H295R cells had different migration potentials after $24 \mathrm{~h}$ of intervention with different concentrations of TUDCA. The group treated with $400 \mu \mathrm{M}$ TUDCA induced the highest percentage of SW-13 cell migration, while $600 \mu \mathrm{M}$ TUDCA induced the highest percentage of NCI-H295R cell migration (Fig. 2A-D). The Transwell assay confirmed that the invasiveness of SW-13 cells was significantly increased in the $400 \mu \mathrm{M}$ TUDCA group compared with that in the $0 \mu \mathrm{M}$ TUDCA group, and the invasiveness of NCI-H295R cells was significantly increased in the $600 \mu \mathrm{M}$ TUDCA group compared with that in the $0 \mu \mathrm{M}$ TUDCA group (Fig. 3A-D).

TUDCA alleviates the influence of ER stress in SW-13 cells. In the present study, whether TUDCA regulated the ER stress pathway in SW-13 cells was investigated using RT-qPCR and western blot analyses. The mRNA expression of the ER stress promoter GRP78 was significantly decreased in the $400 \mu \mathrm{M}$ TUDCA group. In accordance with the changes in mRNA expression, western blot analysis showed that the expression of GRP78 protein was also markedly decreased in the $400 \mu \mathrm{M}$ TUDCA group compared with that in the $0 \mu \mathrm{M}$ TUDCA group after $48 \mathrm{~h}$. Decreased expression of GRP78 alleviated ER stress in SW-13 cells. In addition, the expression of ER-related factors was downregulated with TUDCA treatment; PERK and ATF6 mRNA and protein expression levels were significantly reduced in the $400 \mu \mathrm{M}$ TUDCA group compared with those in the $0 \mu \mathrm{M}$ TUDCA group. The mRNA and protein expression of other downstream factors, CHOP and JNK, also correspondingly decreased with TUDCA treatment. There were no significant differences in the mRNA levels of ER stress-related factors between the $100 \mu \mathrm{M}$ TUDCA group and the $0 \mu \mathrm{M}$ TUDCA group. Therefore, the protein levels of $100 \mu \mathrm{M}$ TUDCA group was not compared using western blot analysis (Fig. 4A-C).

TUDCA induces autophagy and inhibits apoptosis in $S W-13$ cells. LC3 serves as one of the most important markers of autophagy. When autophagy occurs, the LC3-I cytosolic form is converted to the LC3-II lipid-conjugated membrane-bound form (22). Our results showed that LC3-II/I expression increased in a concentration-dependent manner after TUDCA intervention, and LC3-II/I mRNA and protein expression in the $400 \mu \mathrm{M}$ TUDCA group was significantly higher compared with that in the $0 \mu \mathrm{M}$ TUDCA group (Fig. 5A-C). In addition, TUDCA alleviated ER stress and induced autophagy, thereby inhibiting apoptosis. In the $400 \mu \mathrm{M}$ TUDCA group, the expression of the anti-apoptotic factor Bcl-2 was upregulated, and the mRNA and protein expression of Bcl-2 was significantly higher in the $400 \mu \mathrm{M}$ TUDCA group compared with that in the $0 \mu \mathrm{M}$ TUDCA group. However, the mRNA and protein expression of the pro-apoptotic factor Bax exhibited the opposite expression pattern from Bcl-2 (Fig. 6A-C). 

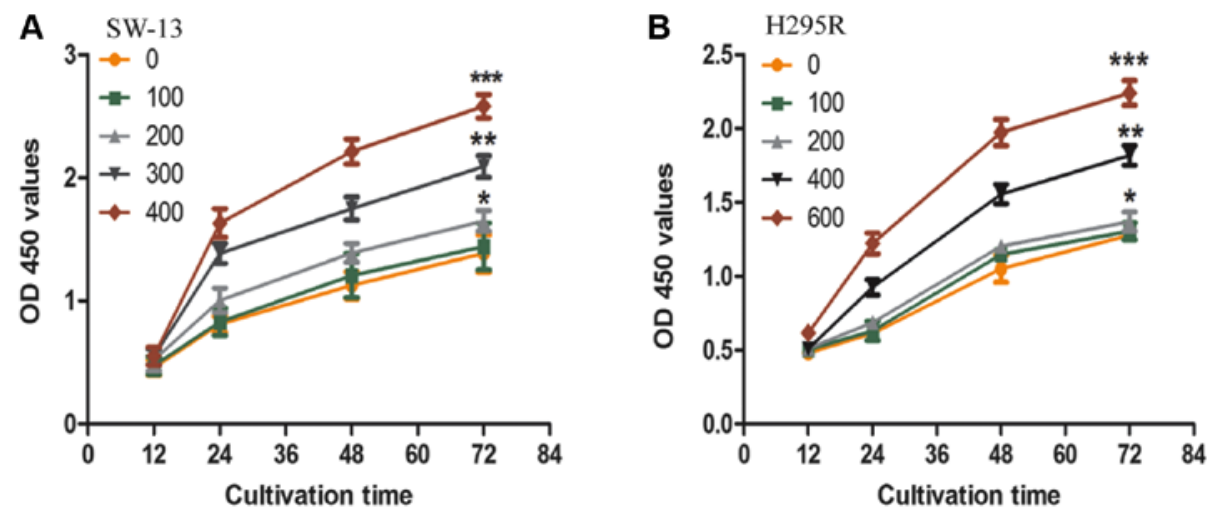

Figure 1. TUDCA promotes the proliferation of SW-13 and NCI-H295R cells. Cell Counting Kit 8 assay was used to determine the effect of TUDCA on the proliferation of (A) SW-13 and (B) NCI-H295R cells at various times and concentrations. ${ }^{* * * * *} \mathrm{P}<0.001,{ }^{* * *} \mathrm{P}<0.01$, and ${ }^{*} \mathrm{P}<0.05$ compared to the $0 \mu \mathrm{M}$ TUDCA group. TUDCA, tauroursodeoxycholic acid; OD, optical density.

A

SW-13

$0 \mathrm{~h}$

$24 \mathrm{~h}$


$100 \mu \mathrm{M}$

B

NCI-H295R

$0 \mathrm{~h}$
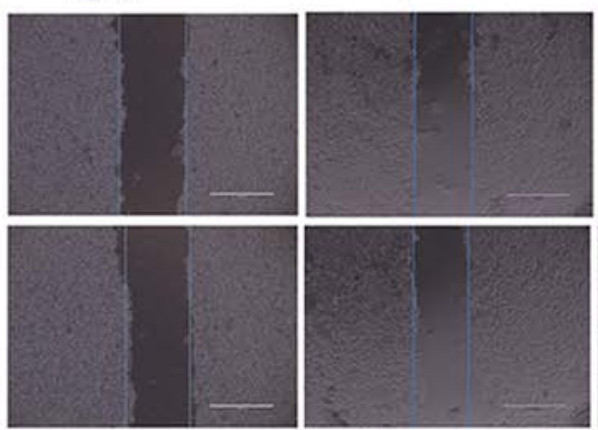

$$
0 \mu \mathrm{M}
$$

$100 \mu \mathrm{M}$

C

SW-13

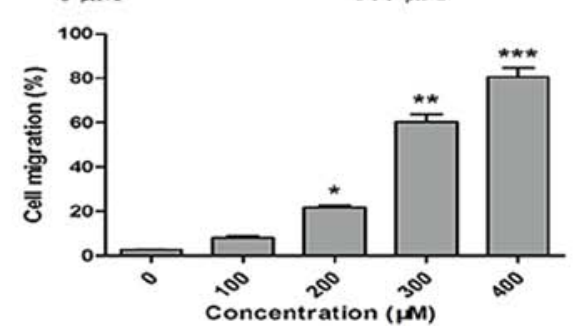

$200 \mu \mathrm{M}$

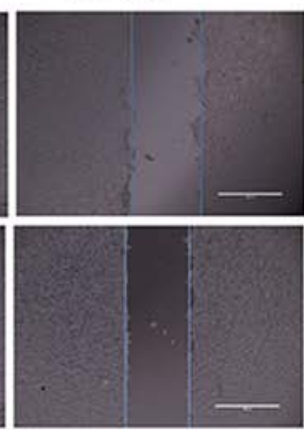

$200 \mu \mathrm{M}$

D

NCI-H295R
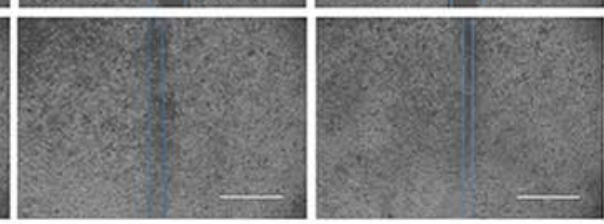

$400 \mu \mathrm{M}$

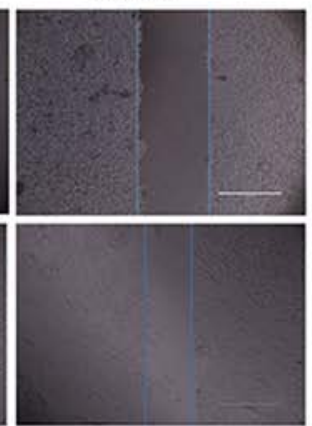

$400 \mu \mathrm{M}$

$600 \mu \mathrm{M}$

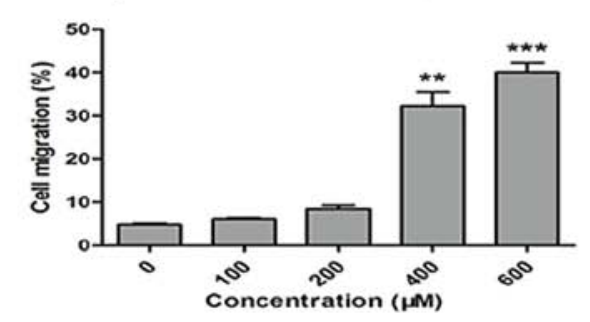

Figure 2. TUDCA promotes the migration of SW-13 and NCI-H295R cells. The migration of (A) SW-13 and (B) NCI-H295R cells was determined using the wound healing assay at 0 and $24 \mathrm{~h}$ with different concentrations of TUDCA. Original magnification, $\mathrm{x} 40$. Relative mobility of (C) SW-13 and (D) NCI-H295R cells. ${ }^{* * *} \mathrm{P}<0.001,{ }^{* * *} \mathrm{P}<0.01$, and ${ }^{*} \mathrm{P}<0.01$ compared to the $0 \mu \mathrm{M}$ TUDCA group. TUDCA, tauroursodeoxycholic acid.

\section{Discussion}

TUDCA is a well-known ER chaperone that alleviates ER stress (23). Activation of the UPR signaling pathway following ER stress plays an important role in tumorigenesis (24). UPR activation involves GRP78, PERK, inositol-requiring protein $1 \alpha$ (IRE1 $\alpha$ ), and ATF6 (25). The competitive binding of GRP78 with the hydrophobic surfaces of misfolded proteins following ER stress releases these transducers to induce UPR signaling. GRP78, the ER promoter, acts as a major regulator of the UPR through directly interacting with the UPR sensors, namely, PERK, 
A

SW-13
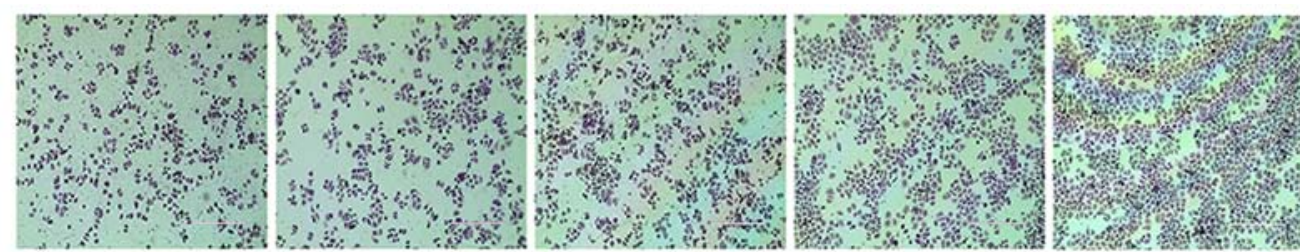

$0 \mu \mathrm{M}$

$100 \mu \mathrm{M}$

$200 \mu \mathrm{M}$

$300 \mu \mathrm{M}$

$400 \mu \mathrm{M}$

B
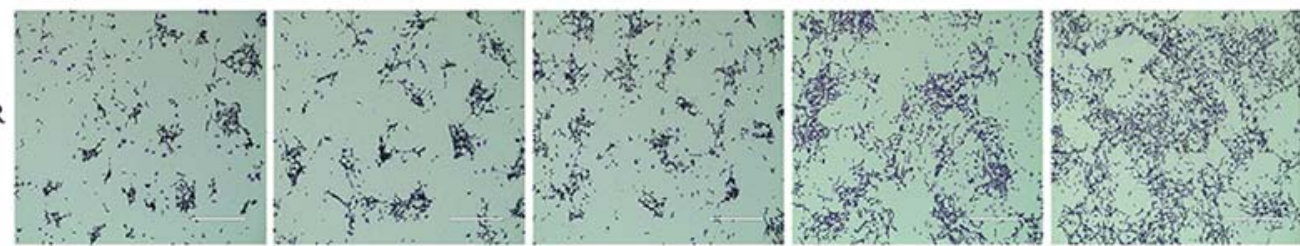

$0 \mu \mathrm{M}$

$100 \mu \mathrm{M}$

$200 \mu \mathrm{M}$

$400 \mu \mathrm{M}$

$600 \mu \mathrm{M}$

C

SW-13



D

NCI-H295R

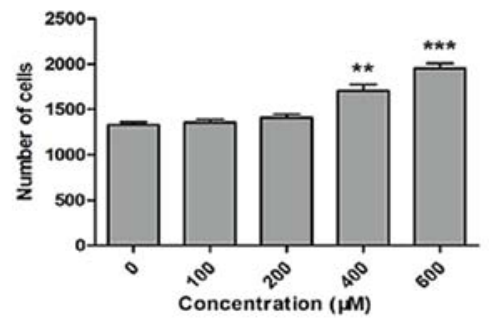

Figure 3. TUDCA promotes the invasiveness of SW-13 and NCI-H295R cells. After $24 \mathrm{~h}$ of TUDCA treatment, the invasive ability of (A) SW-13 and (B) NCI-H295R cells was determined using a Transwell assay. Original magnification, x100. Quantification of the invasiveness of (C) SW-13 and (D) NCI-H295R cells using GraphPad Prism 5.0. ${ }^{* * *} \mathrm{P}<0.001,{ }^{* *} \mathrm{P}<0.01$, and ${ }^{*} \mathrm{P}<0.01$ compared to the $0 \mu \mathrm{M}$ TUDCA group. TUDCA, tauroursodeoxycholic acid.

A

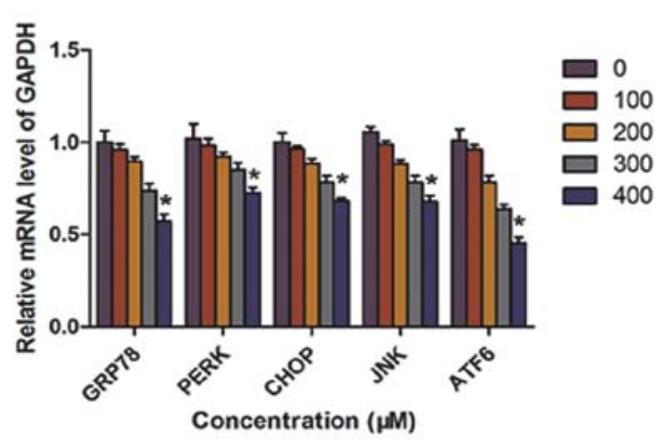

$\mathrm{C}$

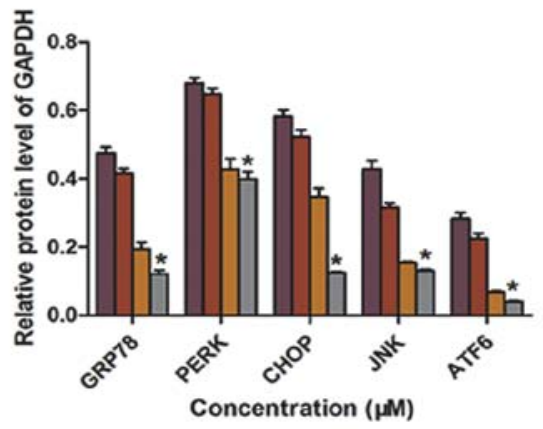

B

GRP78

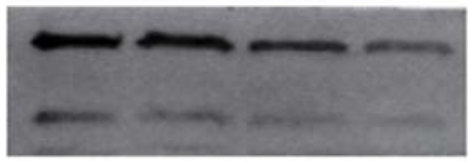

PERK



CHOP

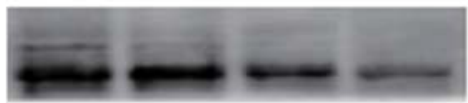

JNK



ATF6

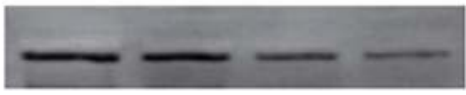

GAPDH

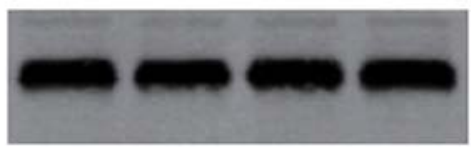

$0 \mu \mathrm{M} \quad 200 \mu \mathrm{M} \quad 300 \mu \mathrm{M} \quad 400 \mu \mathrm{M}$

Figure 4. TUDCA alleviates ER stress in SW-13 cells. After $48 \mathrm{~h}$ of TUDCA intervention, total RNA was extracted and used to detect the mRNA expression of ER stress-related factors using (A) reverse transcription-quantitative PCR and (B) western blot analysis. (C) Quantification of the western blot analysis. ${ }^{*} \mathrm{P}<0.001$ compared to the $0 \mu \mathrm{M}$ TUDCA group. ER endoplasmic reticulum; TUDCA, tauroursodeoxycholic acid; GRP78, glucose-regulated protein 78; PERK, protein kinase-like ER kinase; CHOP, C/EBP homologous protein; ATF6, activating transcription factor 6.

IRE1 $\alpha$, and ATF6 (26). When TUDCA inhibited ER stress, three ER sensors were also inhibited. The dissociation of
GRP78 from PERK, IRE1 $\alpha$, and ATF6 leads to their inhibition. Liu et al (27) administered TUDCA to salivary adenoid 

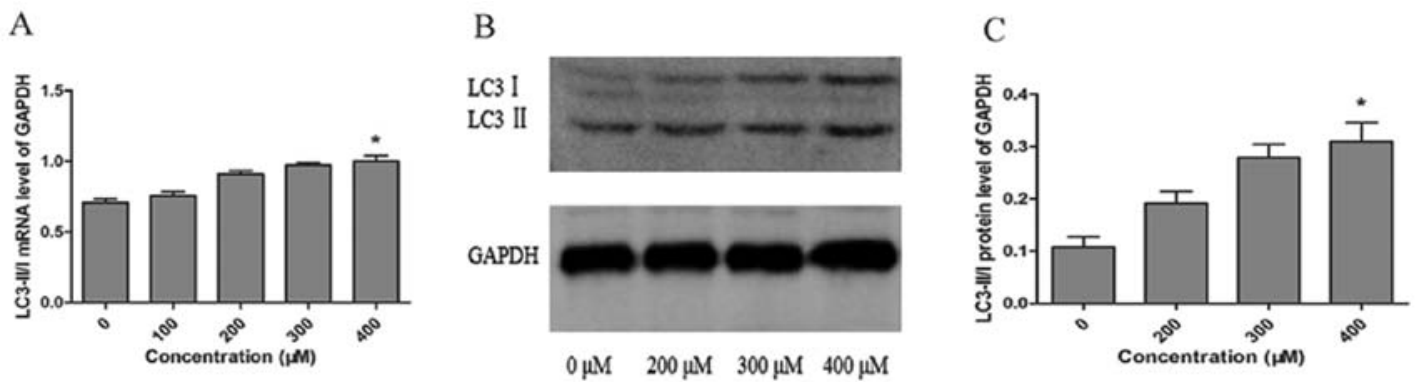

Figure 5. TUDCA-induced autophagy is endoplasmic reticulum stress dependent. SW-13 cells were treated with TUDCA for $48 \mathrm{~h}$. Cells were collected and subjected to (A) reverse transcription-quantitative PCR and (B) western blot analyses using the LC3-II/I marker of autophagy. (C) Quantification of western blot analysis. " $\mathrm{P}<0.001$ compared to the $0 \mu \mathrm{M}$ TUDCA group. TUDCA, tauroursodeoxycholic acid; LC3, microtubule-associated protein light chain 3.

A

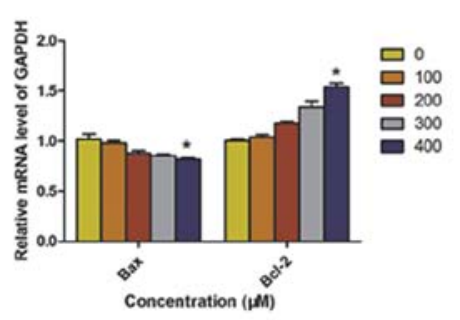

B

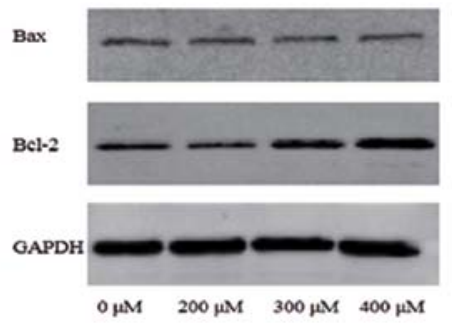

$\mathrm{C}$

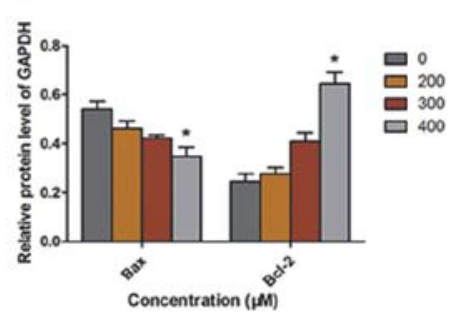

Figure 6. SW-13 cell apoptosis is inhibited after TUDCA intervention. The mRNA expression of Bax and Bcl-2 in SW-13 cells was determined using (A) reverse transcription-quantitative PCR and (B) western blot analysis. (C) Quantification of western blot analysis. ${ }^{*} \mathrm{P}<0.001$ compared to the $0 \mu \mathrm{M}$ TUDCA group. TUDCA, tauroursodeoxycholic acid.

cystic carcinoma cell cultures $3 \mathrm{~h}$ before ceramide treatment. Ceramide-induced X-box binding protein 1 mRNA splicing was significantly inhibited by TUDCA pretreatment, and TUDCA inhibited ceramide-induced eIF2 $\alpha$ phosphorylation. TUDCA alleviated ceramide-induced ER stress. Marquardt et al (28) reported that TUDCA ameliorated maladaptive ER stress signaling and reduced the expression of ATF6 and CHOP. In the present study, it was observed that TUDCA alleviates ER stress and promotes ACC cell proliferation. Thus, ER stress-related signaling pathways play a role in ACC.

Autophagy is important for the secretion of diverse proteins involved in intercellular signaling and cancer progression. Autophagic flux can be upregulated in response to stressful stimuli, such as nutritional, metabolic, oxidative, pathogenic, genotoxic, or proteotoxic stress (29). This stimulus-induced autophagy serves a cytoprotective function by helping cells adapt to stress and promoting cell survival $(30,31)$. As one of the most important markers of autophagy, the transition of LC3 from LC3-I to LC3-II mediates key features of autophagy activation by promoting lysis, lipogenesis, and proteolysis (22). Some studies showed that the PERK-eIF2 $\alpha$-ATF4-CHOP pathway contributed to the ER stress-induced activation of autophagy $(32,33)$. A study by B'Chir et al (32) showed that the LC3-II/LC3-I ratio was increased after knockout of CHOP. CHOP is a downstream indicator of the ER stress signaling pathway and a key participant in apoptosis. CHOP can activate a death program by inducing both the extrinsic and intrinsic apoptotic pathways, decreasing the expression of the anti-apoptotic protein $\mathrm{Bcl}-2$ while increasing the expression of the pro-apoptotic
Bax (34). The present study found that TUDCA alleviated ER stress via the PERK-ATF4-CHOP pathway and induced autophagy in ACC SW-13 cells. Meanwhile, CHOP expression was downregulated, which may inhibit ACC cell apoptosis. A previous study has shown that TUDCA inhibited ER stress in pancreatic cancer cells and blocked the pachymic acid-induced apoptosis of pancreatic cancer (35). These results provide evidence demonstrating that TUDCA alleviated ER stress and induced autophagy in ACC cells, thereby inhibiting the apoptosis of ACC cells.

In conclusion, TUDCA induced autophagy of ACC SW-13 cells and inhibited apoptosis of ACC SW-13 cells after alleviating ER stress of ACC SW-13 cells. ER stress- and autophagy-related signaling pathways are involved in the occurrence of ACC, which may provide potential therapeutic targets for ACC treatment. There is a complex interplay between ER stress and autophagy in ACC. Therefore, an ER stress inducer such as thapsigargin will be used in in vitro and in vivo experiments with $\mathrm{ACC}$ in future studies.

\section{Acknowledgements}

Not applicable.

\section{Funding}

This study was supported by the National Natural Science Foundation of China(grantno.81060220), theInnovation Project of Guangxi Graduate Education (grant no. YCBZ2018037), and the Guangxi Medical and Health Self-financing Project (grant no. Z20180636). 


\section{Availability of data and materials}

The datasets used and/or analyzed during the current study are available from the corresponding author on reasonable request.

\section{Authors' contributions}

$\mathrm{XH}, \mathrm{DL}$ and ZL designed the study. XH, LW, YK, XL, XD, XHL, LL, HY, ZH, DL and ZL conducted the study and analyzed the data. XH wrote the manuscript, and ZL revised the manuscript. All authors read and approved the final manuscript.

\section{Ethics approval and consent to participate}

Not applicable.

\section{Patient consent for publication}

Not applicable.

\section{Competing interests}

The authors declare that they have no competing interests.

\section{References}

1. Xie C, Tanakchi S, Raygada M, Davis JL and Del Rivero J: Case report of an adrenocortical carcinoma associated with germline CHEK2 mutation. J Endocr Soc 3: 284-290, 2018 .

2. Xiao H, Xu D, Chen P, Zeng G, Wang X and Zhang X: Identification of five genes as a potential biomarker for predicting progress and prognosis in adrenocortical carcinoma. J Cancer 9 : 4484-4495, 2018.

3. Li Y, Bian X, Ouyang J, Wei S, He M and Luo Z: Nomograms to predict overall survival and cancer-specific survival in patients with adrenocortical carcinoma. Cancer Manag Res 10: 6949-6959, 2018.

4. Else T, Kim AC, Sabolch A, Raymond VM, Kandathil A, Caoili EM, Jolly S, Miller BS, Giordano TJ and Hammer GD: Adrenocortical carcinoma. Endocr Rev 35: 282-326, 2014.

5. Gonzalez RJ, Tamm EP, Ng C, Phan AT, Vassilopoulou-Sellin R, Perrier ND, Evans DB and Lee JE: Response to mitotane predicts outcome in patients with recurrent adrenal cortical carcinoma Surgery 142: 867-875, 2007.

6. Schteingart DE, Doherty GM, Gauger PG, Giordano TJ, Hammer GD, Korobkin M and Worden FP: Management of patients with adrenal cancer: Recommendations of an international consensus conference. Endocrine-Related Cancer 12: 667-680, 2005

7. Mohan DR, Lerario AM and Hammer GD: Therapeutic targets for adrenocortical carcinoma in the genomics era. J Endocr Soc 2: 1259-1274, 2018

8. Baudin E and Endocrine Tumor Board of Gustave R: Adrenocortical carcinoma. Endocrinol Metab Clin North Am 44: 411-434, 2015

9. Teng Y, Zhao H, Gao L, Zhang W, Shull AY and Shay C: FGF19 protects hepatocellular carcinoma cells against endoplasmic reticulum stress via activation of FGFR4- GSK3 $\beta$-Nrf2 Signaling. Cancer Res 77: 6215-6225, 2017.

10. Kim C and Kim B: Anti-cancer natural products and their bioactive compounds inducing ER stress-mediated apoptosis: A review. Nutrients 10: pii: E1021, 2018.

11. Limonta P, Moretti RM, Marzagalli M, Fontana F, Raimondi M and Montagnani Marelli M: Role of endoplasmic reticulum stress in the anticancer activity of natural compounds. Int $\mathbf{J}$ Mol Sci 20: pii: E961, 2019.

12. Wang M, Law ME, Castellano RK and Law BK: The unfolded protein response as a target for anticancer therapeutics. Crit Rev Oncol Hematol 127: 66-79, 2018
13. Moon HW, Han HG and Jeon YJ: Protein quality control in the endoplasmic reticulum and cancer. Int J Mol Sci 19: pii: E3020, 2018.

14. Zhou F, Yang X, Zhao H, Liu Y, Feng Y, An R, Lv X, Li J and Chen B: Down-regulation of OGT promotes cisplatin resistance by inducing autophagy in ovarian cancer. Theranostics 8 : 5200-5212, 2018.

15. Li S, Guo L, Qian P, Zhao Y, Liu A, Ji F, Chen L, Wu X and Qian G: Lipopolysaccharide induces autophagic cell death through the PERK-dependent branch of the unfolded protein response in human alveolar epithelial A549 cells. Cell Physiol Biochem 36: 2403-2417, 2015.

16. Luchetti F, Crinelli R, Cesarini E, Canonico B, Guidi L, Zerbinati C, Di Sario G, Zamai L, Magnani M, Papa S and Iuliano L: Endothelial cells, endoplasmic reticulum stress and oxysterols. Redox Biol 13: 581-587, 2017.

17. Chen Y, Liu CP, Xu KF, Mao XD, Lu YB, Fang L, Yang JW and Liu C: Effect of taurine-conjugated ursodeoxycholic acid on endoplasmic reticulum stress and apoptosis induced by advanced glycation end products in cultured mouse podocytes. Am J Nephrol 28: 1014-1022, 2008.

18. Yang Y, Tang X, Hao F, Ma Z, Wang Y, Wang L and Gao Y: Bavachin induces apoptosis through mitochondrial regulated ER stress pathway in HepG2 cells. Biol Pharm Bull 41: 198-207, 2018.

19. Guo Q, Shi Q, Li H, Liu J, Wu S, Sun H and Zhou B: Glycolipid metabolism disorder in the liver of obese mice is improved by TUDCA via the restoration of defective hepatic autophagy. Int J Endocrinol 2015: 687938, 2015.

20. Livak KJ and Schmittgen TD: Analysis of relative gene expression data using real-time quantitative PCR and the 2(-Delta Delta $\mathrm{C}(\mathrm{T})$ ) method. Methods 25: 402-408, 2001

21. Li J, Wang Y, Ge J, Li W, Yin L, Zhao Z, Liu S, Qin H, Yang J, Wang L, et al: Doublecortin-like kinase 1 (DCLK1) regulates B cell-specific moloney murine leukemia virus insertion site 1 (Bmi-1) and is associated with metastasis and prognosis in pancreatic cancer. Cell Physiol Biochem 51: 262-277, 2018.

22. Rahman FU, Ali A, Duong HQ, Khan IU, Bhatti MZ, Li ZT, Wang $\mathrm{H}$ and Zhang DW: ONS-donor ligand based $\mathrm{Pt}(\mathrm{II})$ complexes display extremely high anticancer potency through autophagic cell death pathway. Eur J Med Chem 164: 546-561, 2019.

23. Vandewynckel YP, Laukens D, Devisscher L, Paridaens A, Bogaerts E, Verhelst X, Van den Bussche A, Raevens S, Van Steenkiste C, Van Troys M, et al: Tauroursodeoxycholic acid dampens oncogenic apoptosis induced by endoplasmic reticulum stress during hepatocarcinogen exposure. Oncotarget 6: 28011-28025, 2015.

24. Wu CH, Silvers CR, Messing EM and Lee YF: Bladder cancer extracellular vesicles drive tumorigenesis by inducing the unfolded protein response in endoplasmic reticulum of nonmalignant cells. J Biol Chem 294: 3207-3218, 2019.

25. Luo B and Lee AS: The critical roles of endoplasmic reticulum chaperones and unfolded protein response in tumorigenesis and anticancer therapies. Oncogene 32: 805-818, 2013.

26. Guzel E, Arlier S, Guzeloglu-Kayisli O, Tabak MS, Ekiz T, Semerci N, Larsen K, Schatz F, Lockwood CJ and Kayisli UA: Endoplasmic reticulum stress and homeostasis in reproductive physiology and pathology. Int J Mol Sci 18: E792, 2017.

27. Liu Z, Xia Y, Li B, Xu H, Wang C, Liu Y, Li Y, Li C, Gao N and $\mathrm{Li}$ L: Induction of ER stress-mediated apoptosis by ceramide via disruption of $\mathrm{ER} \mathrm{Ca}(2+)$ homeostasis in human adenoid cystic carcinoma cells. Cell Biosci 4: 71, 2014.

28. Marquardt A, Al-Dabet MM, Ghosh S, Kohli S, Manoharan J, ElWakiel A, Gadi I, Bock F, Nazir S and Wang H: Farnesoid X receptor agonism protects against diabetic tubulopathy: Potential add-on therapy for diabetic nephropathy. J Am Soc Nephrol 28: 3182-3189, 2017.

29. Galluzzi L, Pietrocola F, Bravo-San Pedro JM, Amaravadi RK, Baehrecke EH, Cecconi F, Codogno P, Debnath J, Gewirtz DA, Karantza V, et al: Autophagy in malignant transformation and cancer progression. EMBO J 34: 856-880, 2015.

30. Amaravadi R, Kimmelman AC and White E: Recent insights into the function of autophagy in cancer. Genes Dev 30: 1913-1930, 2016.

31. Cotzomi-Ortega I, Aguilar-Alonso P, Reyes-Leyva J and Maycotte P: Autophagy and its role in protein secretion: Implications for cancer therapy. Mediators Inflamm 2018: 4231591,2018 
32. B'Chir W, Chaveroux C, Carraro V, Averous J, Maurin AC, Jousse C, Muranishi Y, Parry L, Fafournoux P and Bruhat A: Dual role for CHOP in the crosstalk between autophagy and apoptosis to determine cell fate in response to amino acid deprivation. Cell Signal 26: 1385-1391, 2014

33. Lei Y, Wang S, Ren B, Wang J, Chen J, Lu J, Zhan S, Fu Y, Huang L and Tan J: CHOP favors endoplasmic reticulum stress-induced apoptosis in hepatocellular carcinoma cells via inhibition of autophagy. PLoS One 12: e0183680, 2017

34. Puthalakath H, O'Reilly LA, Gunn P, Lee L, Kelly PN, HuntingtonND,Hughes PD,MichalakEM,McKimm-BreschkinJ, Motoyama N, et al: ER stress triggers apoptosis by activating BH3-only protein Bim. Cell 129: 1337-1349, 2007.
35. Cheng S, Swanson K, Eliaz I, McClintick JN, Sandusky GE and Sliva D: Pachymic acid inhibits growth and induces apoptosis of pancreatic cancer in vitro and in vivo by targeting ER stress. PLoS One 10: e0122270, 2015.

This work is licensed under a Creative Commons Attribution-NonCommercial-NoDerivatives 4.0 International (CC BY-NC-ND 4.0) License. 